\title{
DESIGN LÚDICO: carrinho para auxiliar o tratamento oncológico infantil
}

\author{
Ana Elise da Silva Gonçalves \\ Universidade Federal de Santa Maria, RS \\ anaelise_sg@hotmail.com \\ Fabiane Vieira Romano \\ Universidade Federal de Santa Maria, RS \\ fabiromano@gmail.com \\ Amara Lúcia Holanda Tavares Battistel \\ Universidade Federal de Santa Maria, RS \\ amarahb@gmail.com
}

\begin{abstract}
Resumo: O presente trabalho, apoiado na necessidade da atuação do designer no âmbito social, apresenta um estudo de caso realizado no Ambulatório de Quimioterapia do Hospital Universitário de Santa Maria (HUSM), reunindo informações acerca do câncer, do tratamento quimioterápico e, principalmente, da carência de meios de entretenimento das crianças, enquanto são submetidas a esse tratamento. Com a proposta do desenvolvimento de um produto que, através da atividade lúdica, possa atenuar o sofrimento causado pelo tratamento oncológico infantil, foram realizadas observações in loco e entrevistas com a equipe médica, bem como, a investigação por parte das graduandas do curso de Terapia Ocupacional da Universidade Federal de Santa Maria (UFSM) sobre as necessidades e desejos manifestados pelas próprias crianças. Acompanhando o roteiro metodológico, surgiram requerimentos de projeto que direcionaram a geração de alternativas para possíveis produtos, resultando na criação de um carrinho no qual o público alvo, além de ter a possibilidade de passear pelo hospital, possa praticar atividades, como desenho, pintura, jogos.
\end{abstract}

Palavras-chaves: design lúdico, social, carrinho infantil, oncologia infantil.

Abstract: This work, supported by the need for designer's action in the social sphere, presents a case study conducted at the Ambulatório de Quimioterapia do Hospital Universitário of Santa Maria (HUSM), gathering information about the cancer, chemotherapy, and especially the lack of means of entertainment for children while they are subjected to this treatment. With the proposed development of a product that, through playful activity, can alleviate the suffering caused by childhood cancer 
treatment, on-site observations and interviews with medical staff were held, as well as the investigation by the graduation students of Occupational Therapy at the Universidade Federal de Santa Maria (UFSM) about the needs and wishes expressed by the children themselves. Following the methodological guide emerged-design requirements that guided the generation of alternatives for possible products, resulting in the creation of a cart in which the target audience, besides having the opportunity to tour the hospital, can practice activities such as drawing, painting, games.

Key-words: playful design, social, infant cart, children's oncology.

\section{INTRODUÇÃO}

Sabe-se que a infância é a fase de maior importância para o desenvolvimento do ser humano, a qual preparará o indivíduo para assumir sua própria tutela na vida adulta. Nesse contexto, o papel da brincadeira é fundamental e imprescindível, auxiliando o enfrentamento de adversidades as quais as crianças podem ser expostas durante o curso da vida, como a separação dos pais, mudança de cidade ou escola, dificuldades de aprendizado, ou mesmo em condições de saúde fragilizada.

No caso da superação de uma doença como o câncer, que é considerado um diagnóstico de elevado impacto social, justamente por representar a causa do maior índice de mortalidade infanto-juvenil por doença no Brasil (INSTITUTO DESIDERATA, 2013), a necessidade de entretenimento, ou de um recurso para externar os sentimentos desenvolvidos em decorrência da doença, se torna evidente. Para tanto, a brincadeira e o brinquedo são primordiais no auxílio do tratamento hospitalar dessa doença. Com a presença do brinquedo e de elementos lúdicos, "o ambiente do tratamento pode ser relacionado ao lazer, deixando de ser apreendido apenas como um local de procedimentos que gera sofrimento" (GOMES et al., 2011).

Para suprir essa necessidade o designer pode e deve atuar como intermediador, já que é detentor de inúmeras capacidades para contribuir amenizando as dificuldades e o sofrimento de pessoas submetidas a qualquer tipo de tratamento de saúde, nesse caso agindo sob o viés social da profissão.

Pazmino (2007) enfatiza a maneira como se dá o envolvimento do Design com causas sociais, que necessitam de maiores atenções:

\footnotetext{
O Design para a sociedade, consiste em desenvolver produtos que atendam às necessidades reais específicas de cidadãos menos favorecidos, social, cultural e economicamente; assim como, algumas populações como pessoas de baixa-renda ou com necessidades especiais devido à idade, saúde, ou inaptidão (PAZMINO, 2007).
}

Além disso, o contato com as criações do designer está intrínseco ao nosso cotidiano. Os objetos são intermediadores de nossas ações e inúmeras decisões que tomamos no dia-a-dia estão relacionadas a eles, que são também responsáveis por promover relações sociais, experiências e comportamentos. Segundo Menezes, 
(...) não podemos construir "produtos com emoção, ou com sentimentos", mas "imaginar e planejar" situações de uso que desencadearão sentimentos positivos. Imaginar e projetar produtos para promover e beneficiar as relações pessoais e sociais dos usuários e promover ações sociais voltadas para o bem comum (MENEZES, 2008).

Portanto o produto do trabalho de Design, além dos acontecimentos do meio, também está atuando e interferindo no psicológico humano, podendo favorecer ou não as experiências de cada indivíduo.

Desse modo, trazer o lúdico ao ambiente hospitalar, neste caso, o Ambulatório de Quimioterapia do Hospital Universitário de Santa Maria (HUSM), se torna imprescindível para auxiliar e facilitar o tratamento oncológico oferecido. Diante da possibilidade de abrandar as experiências dolorosas causadas pelo tratamento de quimioterapia, este trabalho baseia-se no estudo de caso do ambiente citado, com o objetivo geral de desenvolver um produto que proporcione entretenimento e diversão enquanto crianças recebem as medicações apropriadas.

Para a realização do projeto, foram reunidos conceitos metodológicos de diferentes autores, Bonsiepe (1984), Brod Junior e Romano (2013), Baxter (1998) e Löbach (2001), dividindo-os em quatro etapas projetuais: a fase de projeto informacional, que envolve, conforme sua denominação, a reunião de informações necessárias para a orientação do projeto. Trata-se do referencial teórico e pesquisas/registros realizados no ambiente estudado, análises diversas a respeito da situação e produtos existentes e definição de requerimentos do projeto que nortearão sua configuração; a fase de projeto conceitual, a qual compreende procedimentos para a geração de alternativas e a própria geração de alternativas propostas para o projeto, como também o desenvolvimento de modelos tridimensionais caso haja necessidade; a fase de projeto preliminar, onde ocorre a avaliação e definição da melhor alternativa, bem como a realização do produto; a fase de projeto detalhado, quando conclui-se o trabalho com o desenho técnico, a apresentação do modelo funcional e uma análise final do produto.

Pretende-se que o projeto atenue possíveis traumas e sentimentos negativos que possam ter surgido ao longo do tratamento através do resgate do lúdico, tão importante para o auxílio da cura de pacientes infantis.

Esta é uma contribuição importante e necessária do Design à sociedade, que permite à profissão ser real proporcionadora de bem-estar do indivíduo em qualquer circunstância, atendendo à qualidade de vida, que é um fator cada vez mais significativo em nosso dia-a-dia.

\section{DESENVOLVIMENTO}

Muitas são as definições acerca do ofício do designer e pode-se perceber que a grande maioria se caracteriza pelo enfoque no ser humano, o indivíduo que será beneficiado pela criação. Alguns autores dispõem com maior relevância a questão do homem como centro do processo e defendem que esse é o que dá verdadeiro sentido ao Design. A definição, adaptada de Redig (1977/2005), descrita por Gomes e Medeiros no livro Ideias, Ideais e Ideações: para design/desenho industrial (2010), propõe uma reflexão sobre o assunto: 
o Desenho Industrial/Design é o equacionamento simultâneo de fatores Antropológicos (observe o "comportamento" e "ideias" do cliente/ consumidor/usuário); Ecológicos (atente para o ciclo de vida do produto desenhado, "conserve" e "proteja"); Econômicos (perceba que "custo" é um parâmetro, mas o que interessa é o "valor"); Ergonômicos (respeite a natureza humana - a "adequação" - e torne a vida mais "segura e confortável"; Filosóficos (pense que a sua "estética" é a industrial e que a sua "ética" é profissional); Geométricos (habilite-se para simplificar "síntese" - e dominar - "coerência" - as linhas; Mercadológicos (compare a qualidade de um produto com o seu "preço" \& "promoção"; Psicológicos (desenvolva necessariamente a sua "percepção" e "criatividade"; Tecnológicos (estude a obtenção de "materiais" e a "fabricação"), no projeto dos elementos e estruturas destinados ao bem comum e/ou à cultura do homem" (GOMES; MEDEIROS, 2010).

Inúmeros são os campos de atuação do Design, mas as práticas voltadas à melhoria da qualidade de vida das pessoas vêm se fortificando e um exemplo dessa importante proposta é a intervenção do designer no ambiente hospitalar. Tornar estes espaços mais acolhedores e confortáveis aos pacientes pode intensificar os benefícios do tratamento realizado no local. No caso de pacientes infantis, que se encontram em processo de formação física e psicológica e necessitam de um cuidado especial, as brincadeiras no hospital estimulam a troca de experiência e vivência com crianças que compartilham da mesma situação, abrandando o enfrentamento das condições terapêuticas necessárias para a cura.

A agência de publicidade JWT, por exemplo, aliou-se à Warner Bros. e, utilizando o conceito de "Superformula" para ajudar na recuperação dos pacientes, desenvolveu capas para os recipientes dos medicamentos quimioterápicos com a temática dos heróis da Liga da Justiça, como Batman, Lanterna Verde e Mulher Maravilha (Figura 1). A decoração da ala da pediatria do Hospital A. C. Camargo, em São Paulo, integrou o projeto tornando o espaço dos brinquedos a "Sala da Justiça", o qual revela um admirável exemplo de apoio às crianças que enfrentam tratamentos invasivos como o contra o câncer (REVISTA CRESCER, 2013).

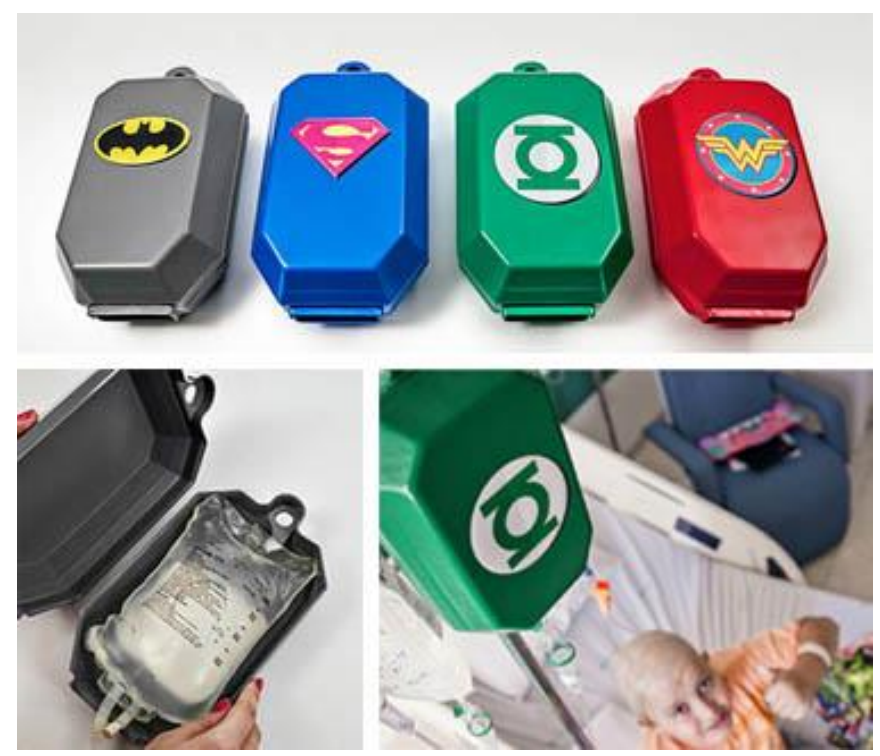

Figura 1: Recipientes para medicamentos quimioterápicos com temática dos heróis da Liga da Justiça. Fonte: Revista Crescer, 2013. 
Diante do diagnóstico avassalador do câncer, principalmente em seres, aparentemente, indefesos, o emocional é um fator de enorme relevância. É preciso ter cuidado para que a criança ou adolescente entenda de forma correta a doença e encontre motivação na família e equipe médica para reagir de forma positiva.

Tão importante quanto o tratamento do câncer em si, é a atenção dada aos
aspectos sociais da doença, uma vez que a criança e o adolescente doentes
devem receber atenção integral, inseridos no seu contexto familiar. A cura
não deve se basear somente na recuperação biológica, mas também no
bem-estar e na qualidade de vida do paciente. Neste sentido, não deve
faltar ao paciente e à sua família, desde o início do tratamento, o suporte
psicossocial necessário, o que envolve o comprometimento de uma equipe
multiprofissional e a relação com diferentes setores da sociedade,
envolvidos no apoio às famílias e à saúde de crianças e jovens (INCA, 2013).

\subsection{O Ambulatório de Quimioterapia do HUSM}

No Ambulatório de Quimioterapia do HUSM o espaço é dividido em dois ambientes. A planta baixa do local (Figura 2) demonstra, de forma aproximada, a maneira como se dá a disposição dos móveis e utensílios necessários para a ministração do tratamento quimioterápico ambulatorial. O círculo vermelho na imagem demonstra uma divisória baixa de, aproximadamente, 1,60m de altura, enquanto o círculo azul aponta uma divisória que acompanha a altura total da sala.

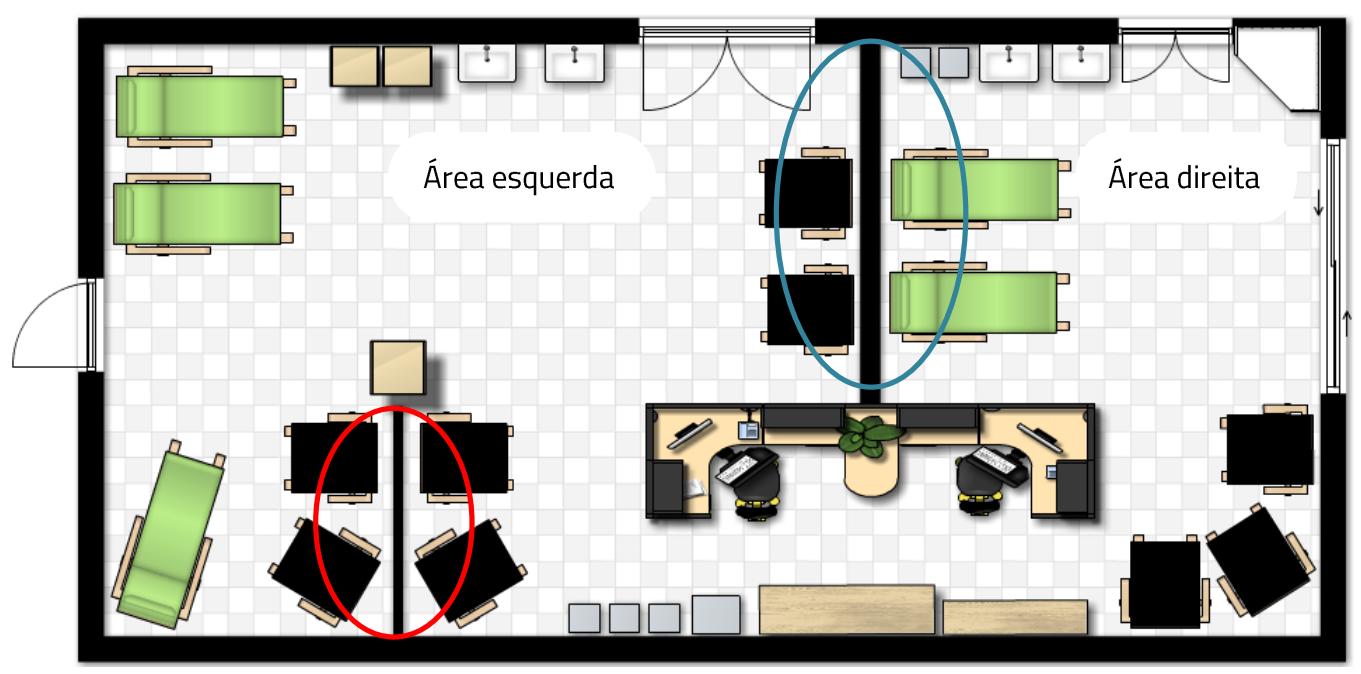

Figura 2: Planta baixa aproximada do Ambulatório de Quimioterapia do HUSM. Elaborado pelo autor, com base na pesquisa realizada.

Entre os dois espaços estão dispostas as poltronas que acomodam os pacientes durante a quimioterapia, lavatórios e instrumentos utilizados para o tratamento, móveis que organizam os documentos necessários para o funcionamento do local e atendimento, e escrivaninhas para que sejam trabalhados os processos burocráticos.

De acordo com a planta baixa aproximada é possível observar que há pouco espaço para circulação e acomodação dos pacientes, considerando-se a presença, ainda, da equipe médica e, por vezes, de terapeutas ocupacionais e psicólogos. Quando os pacientes possuem acompanhantes, como é o caso das crianças, o espaço se torna ainda mais restrito. 
No local são tratados tanto pacientes adultos e idosos, quanto crianças e adolescentes. A duração da sessão de quimioterapia varia de acordo com o tipo e necessidade do tratamento, a qual pode se estender por até sete horas diárias.

Mediante as informações obtidas através de questionários e observações efetuadas no local com o auxílio de graduandas do curso de Terapia Ocupacional da UFSM, foi possível apurar as necessidades e possibilidades de trabalho no ambiente. $E$ dentre essas, observou-se que não há espaço disponível para a intervenção lúdica exclusiva aos pacientes infantis, já que estes compartilham o espaço com os adultos e que o ideal seria o desenvolvimento de um produto que possa ser deslocado.

Também foi investigada a preferência das crianças por determinados tipos de brinquedos e passatempos. Considerando a movimentação limitada em que se encontram, demonstraram preferência por jogos (quebra-cabeça, memória, dominó, caça-palavras), games, desenhar e pintar, assistir a vídeos e ouvir música.

\subsection{Projetando o produto}

Ao longo das observações realizadas no Ambulatório de Quimioterapia do HUSM, uma situação inusitada demonstrou uma maneira divertida de se locomover pelos corredores do hospital: enquanto a criança em tratamento subiu no suporte para soro/medicamento, a mãe fez o suporte andar, como se carregasse seu filho em um passeio. Tal atitude direcionou o projeto para a criação de um carrinho que acomode a criança e o soro/medicamento, necessário para o tratamento, e possa ser utilizado dentro do hospital, evidentemente, procurando obedecer às normas de higienização e segurança necessárias para seu funcionamento.

O projeto, portanto, fundamenta-se na fusão de um suporte para soro/medicamento e um carrinho que permita a movimentação da criança enquanto é submetida ao tratamento quimioterápico, tornando mais divertida sua estadia e auxiliando no desvio do foco na doença e hospitalização para atividades que provoquem contentamento.

O processo metodológico, já mencionado anteriormente, divide-se em quatro fases: projeto informacional, projeto conceitual, projeto preliminar e projeto detalhado.

De acordo com a Metodologia Específica para Educação Projetual e Ensino de Desenho Industrial, a fase de projeto informacional (ou preparação) "permite a construção e a organização de Técnicas Analíticas Linguísticas e Desenhísticas, adequadas para o potenciamento do vocabulário e da fluência projetual dos desenhadores" (BROD JUNIOR; ROMANO, 2013), desse modo, compilou-se todas as informações técnicas e de usabilidade dos suportes para soro/medicamento, carrinhos infantis e andadores, a fim de analisar a estética e o funcionamento desses produtos.

Nesta fase também estudaram-se as exigências de segurança que permeiam a fabricação de produtos voltados ao público infantil. O Inmetro (2013) destaca a avaliação da conformidade dos brinquedos realizada através da Portaria Inmetro 177 desde 1988 no Brasil, a fim de preservar a integridade física e saúde da criança. 
Os brinquedos não devem ter pontas ou extremidades cortantes e partes ou peças pequenas que possam se desprender com facilidade e provocar acidentes. Também não podem ser fabricados ou pintados com material tóxico, uma vez que as crianças costumam desmontá-los, colocando-os, geralmente, na boca, no nariz e nos ouvidos, aumentando a probabilidade de riscos de asfixia, inalação ou intoxicação por via oral, o que pode transformar os brinquedos em verdadeiras armadilhas se não forem bem projetados para a faixa etária a qual se destinam (INMETRO, 2013).

Além dessas considerações, deve-se atentar à higienização dos brinquedos, com o propósito de evitar riscos de infecção ou contaminação. No caso deste trabalho devem ser, excepcionalmente, consideradas as condições de saúde do usuário e o ambiente onde será utilizado o produto, o ambiente hospitalar. Essa condição dispõe de requerimentos específicos de materiais que apresentem possibilidade de eficaz higienização, apresentando superfícies lisas e de fácil acesso.

A partir desses estudos foram definidos os requerimentos de projeto, estes foram organizados em um quadro (Quadro 1 ) e divididos entre estéticos, os quais se referem à forma e aparência do produto, funcionais, que determinam seu funcionamento e técnicos, que determinam a fabricação. Ainda, foram classificados como obrigatórios e desejáveis.

\begin{tabular}{|c|c|c|c|}
\hline & & \multirow[b]{2}{*}{ Obrigatórios } & \multirow[b]{2}{*}{ Desejáveis } \\
\hline & & & \\
\hline \multirow{3}{*}{ 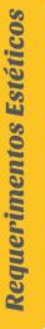 } & $\begin{array}{l}\text { Formas simplese } \\
\text { fluidas }\end{array}$ & & $\begin{array}{l}\text { Devido à necessidade de au- } \\
\text { sência de quinas, é possível } \\
\text { explorar as formas orgânicas } \\
\text { que apresentam fluidez eleveza. }\end{array}$ \\
\hline & Colorido & & $\begin{array}{l}\text { Ainda que o colorido desperte a } \\
\text { atração da criança, há outras } \\
\text { formas de estímulo. }\end{array}$ \\
\hline & Superfície lisa & $\begin{array}{l}\text { É indispensável que a superfície } \\
\text { apresente fácil higienização. }\end{array}$ & \\
\hline \multirow{4}{*}{ 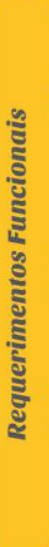 } & Praticidade & $\begin{array}{l}\text { O produto deve apresentar sim- } \\
\text { plicidade e ser intuitivo para que } \\
\text { possa ser facilmente utilizado. }\end{array}$ & \\
\hline & $\begin{array}{l}\text { Multifuncionalida- } \\
\text { de }\end{array}$ & $\begin{array}{l}\text { Além da função de carrinho, de- } \\
\text { ve oferecer suporte para a con- } \\
\text { tinuidade do tratamento qui- } \\
\text { mioterápico. }\end{array}$ & $\begin{array}{l}\text { O ideal é que o carrinho, além da } \\
\text { sua função primária, permita } \\
\text { que as crianças desenvolvam } \\
\text { outras atividades, como jogos e } \\
\text { passatempos. }\end{array}$ \\
\hline & Segurança & $\begin{array}{l}\text { É imprescindivel que o produto } \\
\text { ofereça segurança ao usuário, } \\
\text { principalmente em se tratando } \\
\text { de crianças. }\end{array}$ & \\
\hline & Ergonomia & $\begin{array}{l}\text { Os aspectos ergonômicos de- } \\
\text { vem ser considerados para que } \\
\text { usuário possa permanecer con- } \\
\text { fortável por um tempo razoável. }\end{array}$ & \\
\hline \multirow{2}{*}{ 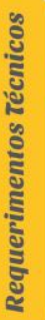 } & Material adequado & $\begin{array}{l}0 \text { material deve ser apropriado } \\
\text { para a eficiência da higienização. }\end{array}$ & \\
\hline & Baixo custo & & $\begin{array}{l}\text { A viabilidade econômica é im- } \\
\text { portante para o produto, consi- } \\
\text { derando-se que este possui va- } \\
\text { lor social. Porém, os materiais } \\
\text { ideais para sua composição po- } \\
\text { dem encarecê-lo, devido à ne- } \\
\text { cessidade de higienização e re- } \\
\text { sistência. }\end{array}$ \\
\hline
\end{tabular}

Quadro 1: Requerimentos de Projeto. Elaborado pelo autor, com base na pesquisa realizada. 
Deu-se início à fase de projeto conceitual onde são geradas alternativas através de desenhos e mocapes em materiais alternativos. Posteriormente é selecionada a alternativa que mais atende às necessidades e requerimentos do projeto iniciando a fase de projeto preliminar. Definida a melhor alternativa (em destaque na Figura 3), parte-se para a realização do modelo funcional.

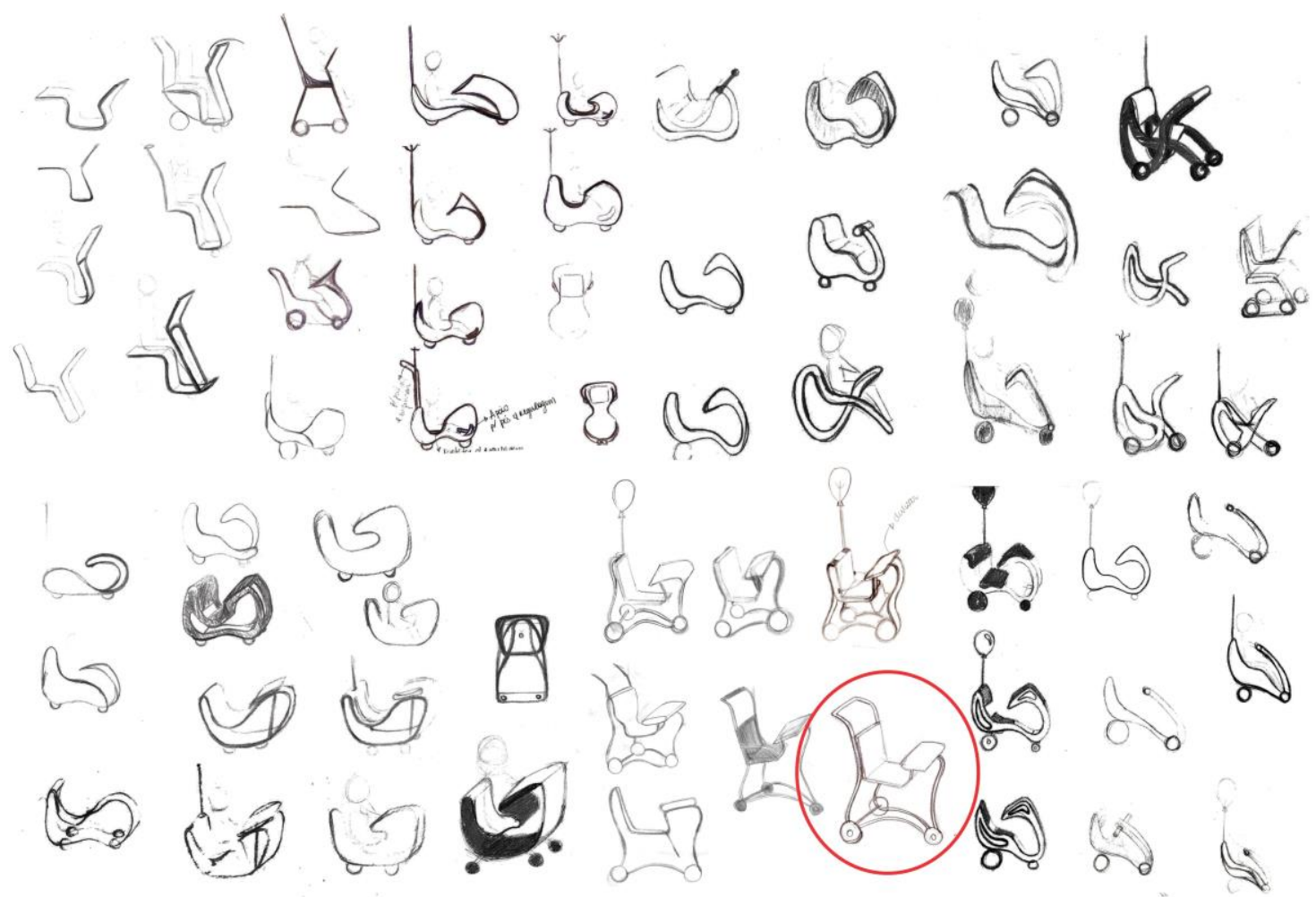

Figura 3: Geração de alternativas. Elaborado pelo autor, com base na pesquisa realizada.

\subsection{Resultados}

Optou-se por trabalhar em tubos de aço inox na estrutura principal do carrinho, já que o material apresenta em suas propriedades resistência a determinadas cargas e ações do tempo, além de permitir fácil higienização. Para os demais componentes optou-se pelo polímero polietileno (PE), o qual pode ser de baixa resistência ao impacto até quase inquebrável, dependendo do tipo, além de possuir uma absorção de umidade quase nula, fácil moldagem e pigmentação, baixo custo e não apresentar toxicidade (LESKO, 2012).

Foram efetuados diversos testes com crianças a fim de que a conformação da estrutura principal do carrinho apresentasse uma configuração de acordo com a proporção antropométrica de possíveis usuários. Na Figura 4 pode-se observar as modificações realizadas, como a inclinação e redução da base para a prancheta de atividades, o aumento da curvatura na parte traseira da estrutura para favorecer a estabilidade e redução da estrutura do assento. 


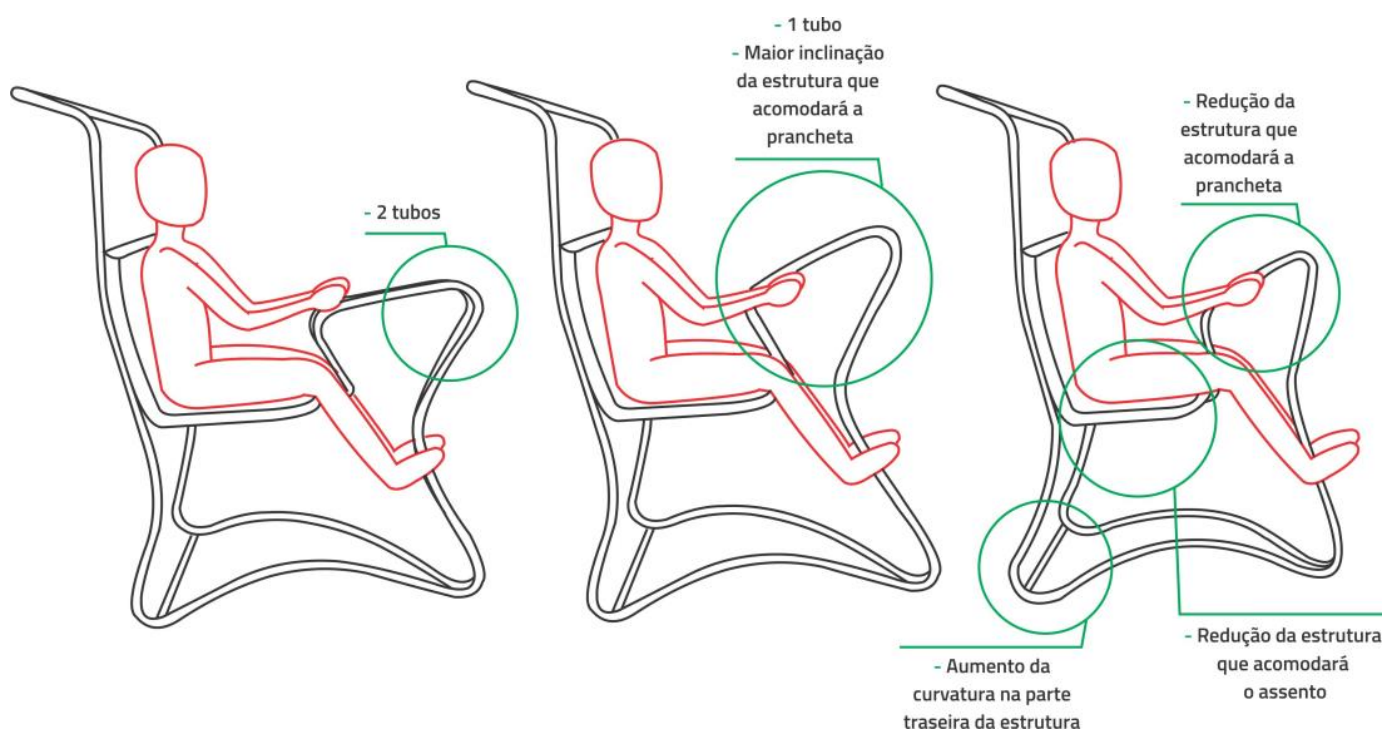

Figura 4: Esquema para compreensão das modificações efetuadas na estrutura principal do carrinho. Elaborado pelo autor, com base na pesquisa realizada.

A fase de projeto detalhado resultou, então, no modelo funcional: a configuração de um carrinho com suporte para soro/medicamento e prancheta de atividades (Figura 5) para que as crianças possam usufruir de entretenimento no ambiente hospitalar enquanto são submetidas ao tratamento quimioterápico.
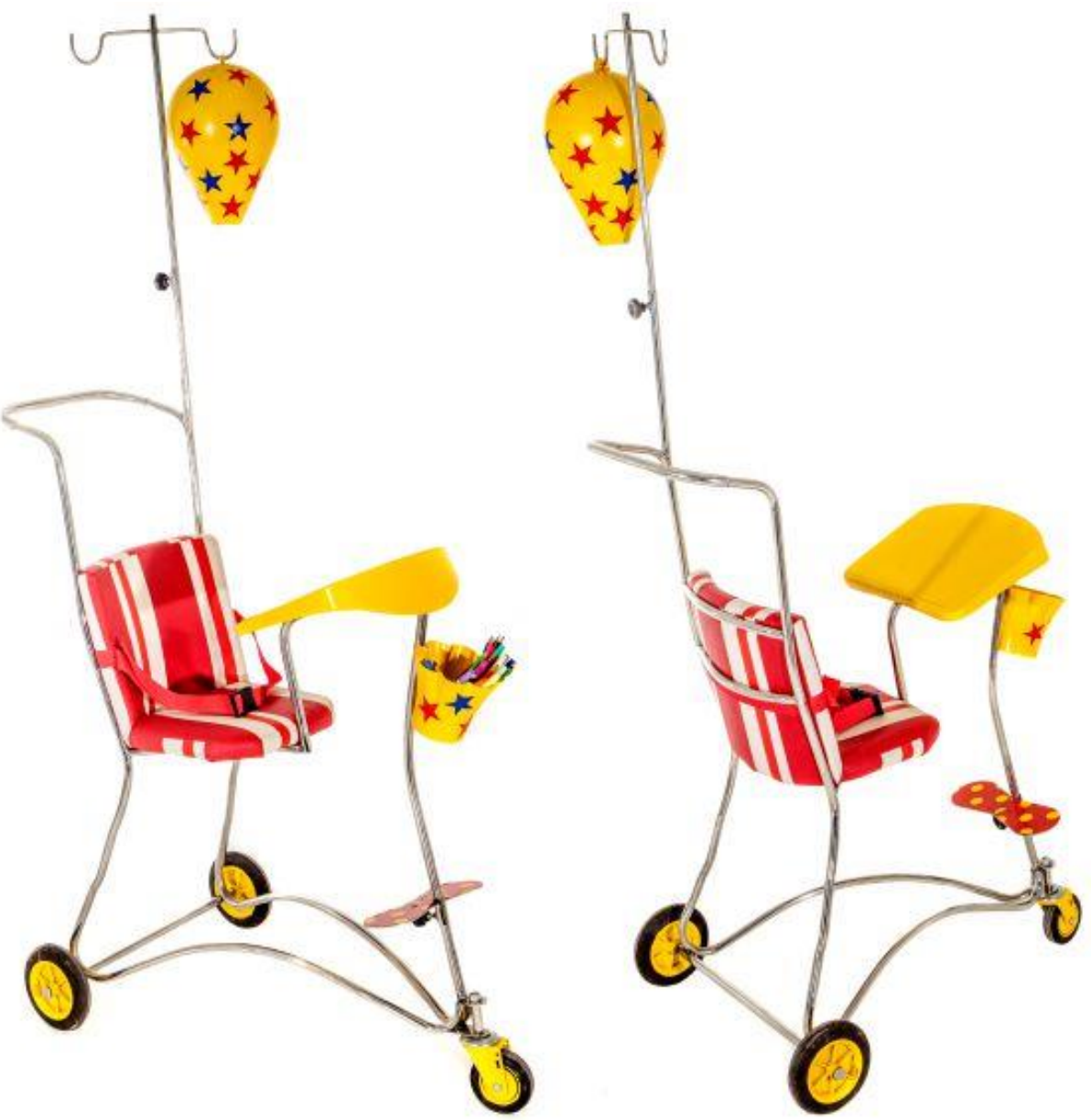

Figura 5: Carrinho lúdico para auxiliar o tratamento oncológico infantil. 
Uma vez que um dos objetivos deste trabalho é promover a relação emocional do usuário com o produto, durante o processo definiu-se uma temática para que suas características viessem a estimular ainda mais seu envolvimento com o usuário. Escolheu-se, então a temática de circo, a fim de conferir ao objeto a atmosfera mágica e emocionalmente excitante do conceito circense, partindo-se da consciência de que o espetáculo possui o propósito de fomentar agradáveis e felizes lembranças.

Após a finalização, o modelo do carrinho foi levado ao Ambulatório de Quimioterapia do HUSM para que fosse avaliado, tanto pelos profissionais que lá atuam, quanto pelos pais e os pacientes pediátricos, que serão usuários deste produto (Figura 6; Figura 7).

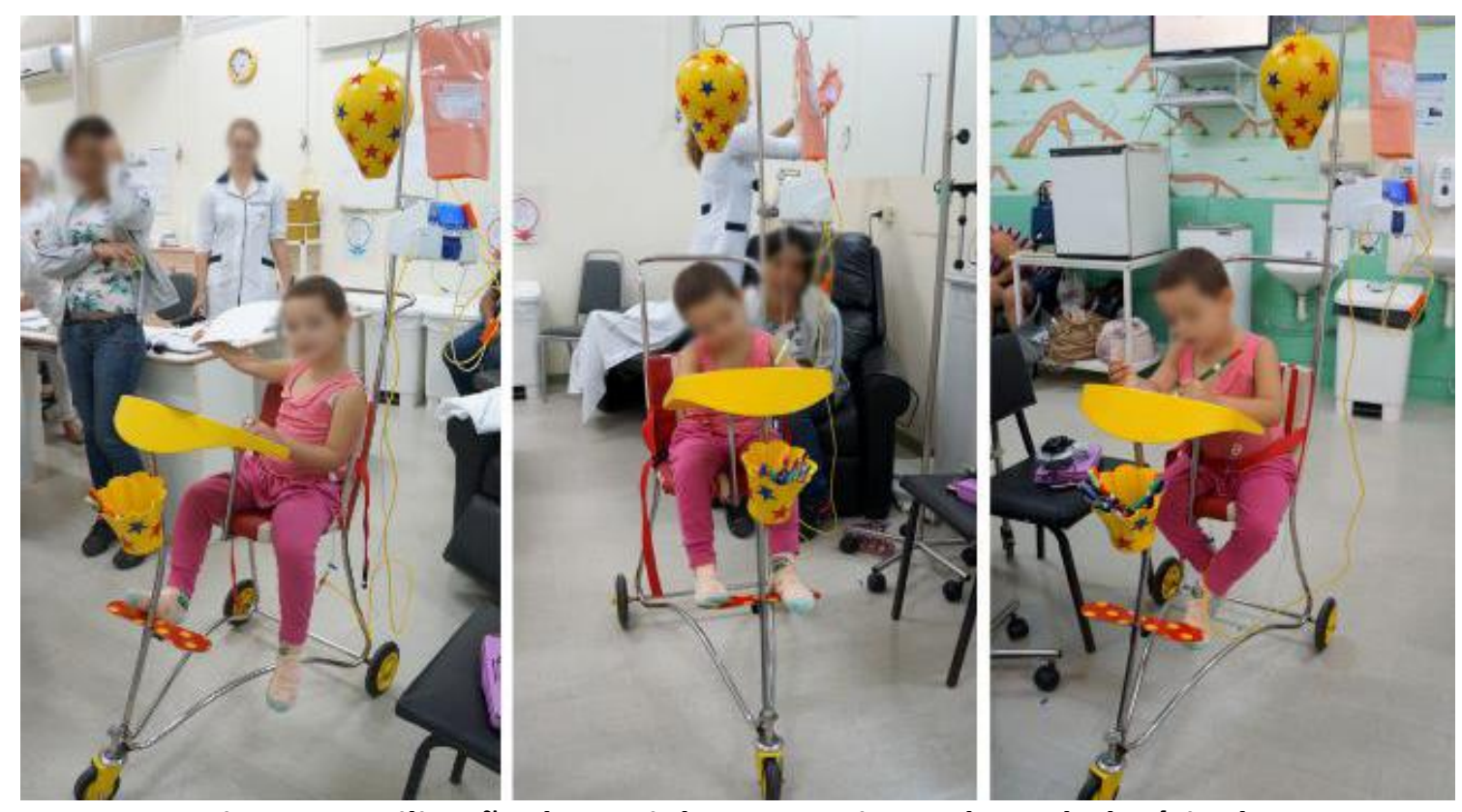

Figura 6: Utilização do carrinho por paciente do Ambulatório de Quimioterapia do HUSM.

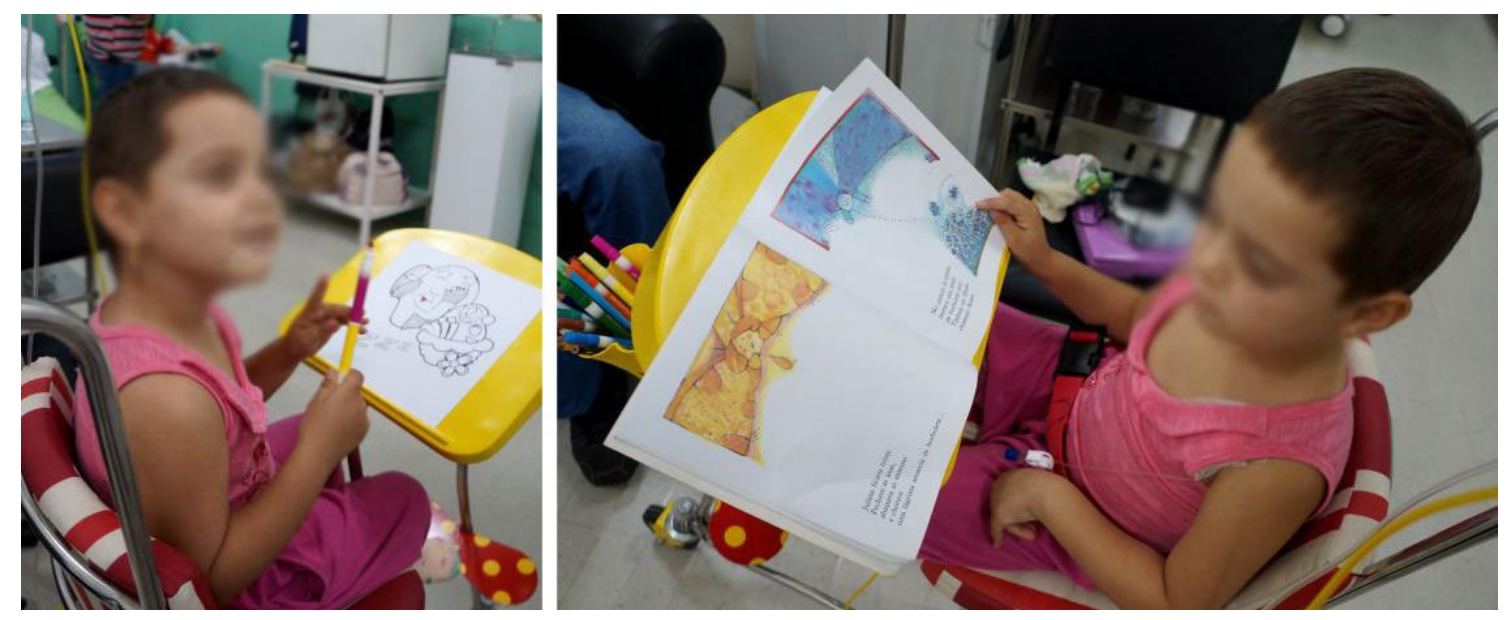

Figura 7: Paciente do Ambulatório de Quimioterapia do HUSM pintando desenhos e lendo historinhas no carrinho. 
As respostas ao produto foram bastante positivas, tanto pelos usuários (pacientes oncológicos de faixa etária entre 4 e 10 anos), quanto pelos pais e profissionais que atuam no ambiente hospitalar.

O produto se mostrou adequado em sua totalidade para atender às proporções corporais de diferentes faixas etárias de crianças, devido à regulagem do apoio para os pés e do suporte para soro/medicamento, possibilitando que um número maior de crianças se beneficiem da intervenção lúdica no local de tratamento.

\section{CONCLUSÃO}

Este foi um trabalho desafiador, envolvendo, não somente as habilidades técnicas do designer, mas, também, as emocionais, a fim de que houvesse sensibilidade o suficiente para engajar-se no mundo infantil, o qual, geralmente, imerso na fantasia e no sonho, dificulta o entendimento de como é possível enfrentar uma doença que lhes rouba a convivência com a família, os amigos, o lar, os brinquedos e, não poucas vezes, a vida.

Além de promover a experiência no ambiente hospitalar, o contato com crianças em tratamento e o modo de enfrentar uma doença séria como o câncer, este trabalho permitiu a observação dos sentimentos que envolvem os pacientes nas condições em que se encontram. As emoções permeiam a vida em todos os momentos, afinal, "sem diversão e prazer, alegria e entusiasmo, e até ansiedade e raiva, medo e fúria, nossas vidas seriam incompletas" (Norman, 2008).

Através deste projeto, cumpriu-se o objetivo de obtenção de um mecanismo de entretenimento e diversão no ambiente de tratamento referido. Por meio do resgate do lúdico, obteve-se como resultado um carrinho que, além de permitir passeios pelo hospital, possibilita que outras atividades sejam praticadas através da prancheta de apoio. Geralmente, a locomoção na área hospitalar é feita com a utilização de cadeira de rodas, o que remete à sensação de incapacidade, limitação, doença. Neste caso, o design lúdico transforma o simples ato de se locomover em uma brincadeira, transmitindo alegria, possibilidade de aventura e descobrimento. Portanto, este trabalho vem a auxiliar o tratamento oncológico de maneira subjetiva para a criança, afinal "é por intermédio do brincar que ela poderá aproveitar os recursos físicos disponíveis naquele contexto para elaborar a nova situação" (MELLO et al., 1999).

Os resultados obtidos com o trabalho foram satisfatórios, já que o protótipo pode ser configurado de maneira que pudesse ser experimentado pelos usuários, 0 que permitiu demonstrar sua eficiência e funcionalidade de acordo com a proposta. 0 produto mostrou-se adequado ao ambiente hospitalar por sua facilidade de higienização e, ainda, às proporções antropométricas de crianças de idades diversificadas. Além disso, favoreceu a possibilidade de utilizá-lo, não apenas no Ambulatório de Quimioterapia do Hospital Universitário de Santa Maria, mas em qualquer unidade de tratamento para crianças nos hospitais, permitindo, através do suporte para soro/medicamento que, até mesmo, crianças acamadas possam brincar.

Em suma, com a implantação do projeto, espera-se que o efeito seja o mais gratificante possível, de maneira que torne a estadia no hospital mais divertida e menos dolorosa para as crianças que ali são submetidas a tratamentos. 


\section{REFERÊNCIAS}

BAXTER, Mike. Projeto de produto: guia prático para o design de novos produtos. 2. ed. São Paulo: Edgard Blücher, 1998.

BONSIEPE, Gui; et al. Metodologia experimental: desenho industrial/coordenação Gui Bonsiepe. Brasília: CNPq/Coordenação Editorial, 1984.

BROD JUNIOR, Marcos; ROMANO, Fabiane Vieira. Metodologia Específica para Educação Projetual e Ensino de Desenho Industrial. Notas de aula da disciplina Teoria e Metodologia do Desenho Industrial, Curso de Desenho Industrial, UFSM, 2013.

GOMES, Isabelle P.; COLLET, Neusa; REIS, Paula E. D. Ambulatório de Quimioterapia: A experiência no Aquário Carioca. Texto Contexto Enferm, Florianópolis, 2011. Jul-Set; 20(3): 585-91;

GOMES, Luiz Antonio Vidal de Negreiros; MEDEIROS, Ligia Sampaio de. Ideias, ideais e ideações: para design/desenho industrial. Porto Alegre: Uniritter, 2010.

INADEC. Brinquedos: uma cartilha em defesa do consumidor. 2013. Disponível em: <http://www.inadec.org.br/cartilhas/brin.pdf>. Acesso em 09 set. 2013.

INCA. Particularidades do Câncer Infantil. 2013. Disponível em:

<http://www.inca.gov.br/conteudo_view.asp?id=343>. Acesso em: 22 jun. 2013.

INMETRO. Brinquedos. Disponível em:

<http://www.inmetro.gov.br/imprensa/releases/brinquedos.asp>. Acesso em: 09 set. 2013.

INSTITUTO DESIDERATA. Como atuamos. 2013. Disponível em:

<http://www.desiderata.org.br/OncComoAtuamos>. Acesso em: 5 jun. 2013.

LESKO, Jim. Design industrial: guia de materiais e fabricação. 2. Ed. São Paulo: Blucher, 2012.

LÖBACH, Bernd. Design Industrial: Bases para a configuração dos produtos industriais. São Paulo: Edgard Blücher, 2001.

MELLO, Cátia Olivier; et al. Brincar no hospital: assunto para discutir e praticar. Psicologia: Teoria e Pesquisa. Brasília, Jan-Abr 1999, Vol. 15 n. 1, pp. 065-074.

MENEZES, Cris. Design \& Emoção. Revista abcDesign, Curitiba, n. 24, p. 28-29, jun. 2008.

NORMAN, Donald. Design Emocional: por que adoramos (ou detestamos) os objetos do dia-a-dia. Rocco, 2008.

PAZMINO, Ana V. Uma reflexão sobre Design Social, Eco Design e Design Sustentável. I Simpósio Brasileiro de Design Sustentável. Curitiba, 4-6 set. 2007.

REVISTA CRESCER. Super-heróis são aliados de hospital paulista para tratar crianças com câncer. Disponível em:

$<$ http://revistacrescer.globo.com/Criancas/Saude/noticia/2013/05/super-herois-saoaliados-de-hospital-paulista-para-tratar-criancas-com-cancer.html>. Acesso em: 7 maio 2013. 